\section{Immunohistological detection of Legionella pneumophila in lung sections}

We were interested in the results reported by Theaker $e a^{1}$ in relation to the well publicised outbreak in Stafford to which they refer. We draw your readers' attention to a similar but less extensive investigation ${ }^{2}$ of the equally well publicised "Benidorm" episode, ${ }^{3}$ performed before monoclonal antibodies were generally available. Organisms have also been shown in tissue sections by a glucose oxidase immunoenzyme technique. ${ }^{4}$

Although the negative cases reported by Theaker et $a l^{1}$ are likely to be genuine, we draw their attention to the range of results in our publication. ${ }^{2}$ Some organisms did not stain with the type specific antisera because the patient's antibody was coating them. While it is possible that some of the negative results reported by Theaker et al may be due to the same blocking process, their use of trypsin might have assisted in unblocking the bacterial antigen. We did not use prestaining digestion with trypsin.

As the authors suggest, the histopathological study of tissue from patients with pneumonia both during life and after death has been advanced considerably by these and other staining procedures.

JF BOYD

E MCWILLIAMS

Brownlee Laboratory,

Ruchill Hospital, Glasgow G20 9NB,

Pathology Department, Western Infirmary, Glasgow G11 6NT.

\section{References}

1 Theaker JM, Tobin J O'H, Jones SEC, et al. Immunohistological detection of Legionella pneumophila in lung sections. $J$ Clin Pathol 1987;40:143-6.

2 Boyd JF, McWilliams E. Immunoperoxidase staining of Legionella pneumophila. Histopathol 1982;6:191-6.

3 Boyd JF, Buchanan W, MacLeod TIF, et al. Pathology of five Scottish deaths from pneumonic illnesses acquired in Spain due to Legionnaires' disease agent. J Clin Pathol 1978;31:809-16.

4 Suffin SC, Kaufmann AF, Whitaker B, et al. Legionella pneumophila. Identification in tissue sections by a new immunoenzymatic procedure. Arch Pathol Lab Med 1980;104:283-6.
Determination of end point of edetic acid decalcification

For acidic methods of decalcification the commonly used method for determining whether decalcification is complete is ammonium oxalate (AO) to precipitate the $\mathrm{Ca}^{2+}$ from the decalcifying fluid. When no more Ca-oxalate precipitate is seen in the most recent change of decalcifying fluid, then the decalcification is completed.

Although Kiernan ${ }^{1}$ claimed that AO could be used to determine the end point of decalcification with disodium ethylenediamine tetra-acetic acid, all other authors recommend radiology or physical methods, such as cutting, bending, or needling, ${ }^{2-4}$ or even weighing. ${ }^{5}$ Culling et $a l^{6}$ stated that the ammonium oxalate method does not work with edetic acid, and this is the general experience.

A simple way to free the calcium from the chelate is to pour the edetic acid decalcifying fluid into a crucible, evaporate to dryness, and then let the residue char. It is important that no white desiccated but not decomposed edetic acid is left. When cool, the inorganic salts are dissolved in $10 \%$ hydrochloric acid. Because there are carbo: particles in this solution, it is necessary to filter it before making alkaline with ammo nia and adding the saturated ammoniun oxalate solution. ${ }^{1-36}$

A similar result would be achieved $b$. using an atomic absorption spec trophotometer to pyrolise the Ca-edeti. complex and directly detect if calcium is present.

L LUDDINGTON PGI STOVIN CG KNIGHT Strangeways Research Laboratories, Worts Causeway, Cambridge CBI 4RN.

References

1 Kiernan JA. Histological and histochemical methods. Theory and practice. Oxford: Pergamon Press, 1981:25-8.

2 Drury RAB, Wallington EA. Carleton's histological technique. Sth ed. Oxford: Oxford University Press, 1980:200-5.

3 Bancroft JD, Stevens A. Theory and practice of histological techniques. 2nd ed. Edinburgh: Churchill Livingstone, 1982:305-10.

4 Brain EB. The preparation of decalcified sections. Springfield: Charles C Thomas, 1966:136.

5 Goncalves RP, Oliver IG. Electrical decalcification of bone. Mikroskopie 1965;20:154-6.

6 Culling CFA, Allison RT, Barr WT. Cellular pathology technique. 4th ed. London: Butterworths, 1985:415.

\section{Book reviews}

Cytology of Body Cavity Fluids. A Colour $\stackrel{\vec{O}}{\stackrel{D}{9}}$ Atlas. EB Butler, CM Stanbridge. (Pp 70; £30.) Chapman and Hall Medical. ISBN 0-412-25600-2.

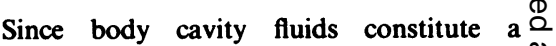
significant part of the workload of every $\stackrel{\omega}{\omega}$ diagnostic cytopathology laboratory, a new $\vec{\circ}$ British monograph on this subject is welcome. The book begins with a section on the $\overrightarrow{\vec{\omega}}$ appearances seen in specimens from normal $\sigma$ patients. Today when peritoneal lavage is $\overrightarrow{0}$ increasingly being performed at laparotomy, this is a valuable feature since the cellular $\vec{\circ}$ patterns may differ considerably from those $V$ seen in paracentesis specimens. This chapter $\infty$ is followed by an account of non-malignant $\vec{T}$ conditions, but the major portion of the ? book is devoted to malignant disease includ- 윽 ing mesothelial, epithelial, and non- epithelial lesions. The techniques described $\subseteq$ and illustrated are largely standard laboratory methods, with conventional Papa- $\vec{c}$ nicolaou and Romanowsky staining. $A \infty$ small section is devoted to the features seen. in cell block preparations using the transmission electron microscope. The illustrations are somewhat uneven in quality, both in colour and in black and white. While this may perhaps be unavoidable with some $\frac{\text { }}{\mathbb{Q}}$ specimens, it detracts to some extent from 2 the usefulness of this monograph as a basic $\overline{\overline{0}}$ laboratory handbook.

HELENA E HUGHES

Atlas of Urinary Sediments. Diagnosis and Clinical Correlations in Nephrology. G Piccoli, D Varese, M Rotunno. (Pp 210; $\$ 82.50$.) The Raven Press. 1984. ISBN 0-890004-507-0.

This is a beautifully illustrated atlas which is basically subdivided into a section dealing $\%$ with the morphological aspects of different $N$ constituents of urine-that is, red cells, $N$ white cells, crystals, etc. This is well done $\omega$ and appropriately illustrated. While commenting on the recent interest in

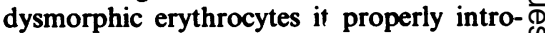
duces a cautionary note with respect to urine? deposits in which it is not possible to sepa- $\square$ rate "glomerular" from "non-glomerular" haematuria. This section is very detailed and especially important in that it illustrates $\overparen{D}$ "artefacts" which may confuse the inexperienced microscopist. 